\title{
The Role of Architectural Competition in the Learning Process of Architecture Students
}

\author{
M. Galieh Gunagama \\ Department of Architecture \\ Universitas Islam Indonesia \\ Yogyakarta, Indonesia \\ galieh.gunagama@uii.ac.id
}

\author{
Yulia Pratiwi \\ Department of Architecture \\ Universitas Islam Indonesia \\ Yogyakarta, Indonesia \\ yulia.pratiwi@uii.ac.id
}

\begin{abstract}
The architectural competition nowadays is growing rapidly. Everyone can easily access information about various architectural competitions via the internet. Myriad options, such as themes, levels, fees, and prizes, are offered in the architectural competition. Either architecture professionals and students from any country in the world can participate in it.
\end{abstract}

The participation of architecture students in architectural competition has increased, as happened in the Department of Architecture Universitas Islam Indonesia. As an activity outside the formal education system, architectural competition thought to be able to improve students' ability to design. The reflective evaluation needs to be done with students to understand what happened in the activity from the student perspective. This paper seeks to find out the role of an architectural competition in the student learning process. In particular, to know what benefits students can gain through their participation in the event.

The method used in this paper is by conducting a reflective questionnaire for students and alumni who have participated in various architectural competitions. The most important benefit of participating in such activities felt by students is that they can add new insights that are not obtained through lectures. It surpass the other benefit, such as in improving the ability to design, the ability to socialize through teamwork, the ability to manage time, the skills to use architectural software and visualization, the skills to deliver oral and written presentations, additional experiences through field studies, understanding of contextual matters that are currently happen, and financial gain. Architectural competition has a good effect and can be a way to build student character. Student participation in architectural competition needs to be an integral part of the student learning process because, in the long term, it can create a more sustainable architecture education system.

Keywords: architectural education, architectural competition, student learning process

\section{RESEARCH BACKGROUND}

Competition is an activity that has existed since the beginning of human civilization. Texts about it can be referred back from the story of Ramayana and Mahabharata in the East, to the account of the Pantheon Gods in the West. In particular, the origins of architectural competitions in the West can refer to ancient Greek myths surrounding the holding of the Olympics. In honor of Zeus at Olympus, Heracles built the first stadium with the length of 200 -Heracles step. This building is an ancient Greek unit of calculation that forms the basis for measuring new types of sports buildings [1].

Although Emperor Theodosius I banned it in 393 AD, the Olympics revived after a 1500 -year suspended animation by Pierre de Coubertin in Athens in 1896. The architecture was one of the branches that had been celebrated under the art category. But it was then separated from the Olympics since 1948 because of many criticisms that arise. Talks about the number of professional artists participating and not amateurs are considered to cause inequality. The disagreement has led to an overhaul of the concept of organizing the modern Olympics [1].

According to Andersson, Zettersten, \& Rönn [1], at first, the architectural competition was limited, and the opportunity to participate only given to selected people or artists with a reputation. The French Revolution transformed architectural competition into an instrument for a new system based on fraternity, equality, and independence, which manifested in architecture itself ${ }^{l}$. It is this spirit that will later become the basis of organizing architectural competitions throughout the world.

The International Union of Architects (UIA) states that architectural competition is a procedure in architectural services that based on quality and oriented to the selection of solutions as the best way to achieve a quality built environment [2]. The competition provides the best solution for real assignments, selected from several entries by the jury, most of whom are professionals. This process is to guarantee the highest performance and the most optimal concept for all clients and users.

The development of architectural competition is now growing rapidly. Every time, architectural competitions, both nationally and internationally, can be easily accessed by students via the internet. The internet itself that has become a common and with high-speed capacity has made it easier for students to get as much information as possible. Something similar was not seen in the past 10 or 5 years.

The theme offered in the architectural competition is not limited to building design, but also includes fields that are closely related to architecture. Such as extensive and meticulous regional planning to pure artistic expression. The cost range for participation started from free to paid, as well

\footnotetext{
${ }^{1}$ Cited form Szambien (1986) in Andersson, Zettersten, \& Rönn (2016).
} 
Architectural competition can be seen as a way of balancing various kinds of specific needs or concerns, such as optimization and efficiency, on the one hand, and creativity and innovation on the other ${ }^{2}$. The competitive advantage of an architectural competition is that it can be a way for contractors to get suitable alternative partners and projects. And always have the opportunity to dialogue and choose at an early stage without compromising the need for equality and efficiency [4].

\section{B. Importance of Architectural Competition in Education}

The task of higher education institutions is to educate ordinary people to become civilized human beings and to become the ideal example of their profession ${ }^{3}$. For the task to be complete, namely aligning scientific studies and the cultural studies, external education, which is complementary to professional training, is urgently needed [5].

To get professional knowledge in the field of architecture, one must enter the school of architecture as a formal education. However, not a single school can educate architects to build creativity and passion. It is imperative for an architect always to uphold the philosophy of the architect, and continuously learn from the environment and experience to develop their professionalism ${ }^{4}$.

The combination of theoretical information and professional practice is one of the skills that students get through informal education. Skills refer to competencies to carry out activities based on particular capabilities, knowledge, attitude, and behavior. In the "UNESCO-UIA Charter for Architectural Education" in 2017 stated that the capabilities that students have to obtain in architectural education identified as "Design", "Knowledge" (Cultural and Artistic Studies, Social Studies, Environmental Studies, Technical Studies, Design Studies and Professional Studies), and "Skills" (collaboration, communicate ideas, utilize various media to create designs, etc.) [6].

This notion can be interpreted that architecture students must have a complete understanding from both sides to work well in the professional field. Collaboration between formal and informal education, which complement each other, enables the process of gaining skills for students from both sides to run smoothly [5].

Today, architectural education has become independent and exceeds the limits of architecture that were once recognized. A more dynamic process has replaced the relatively rigid architecture education system. The academic atmosphere of architecture, which was initially dominated by certain styles that had to follow the rules and types agreed upon by the status quo, had turned into experimental architecture $^{5}$. This condition should also be supported by innovation in teaching architecture. Instead of choosing to equip the studio with a variety of informal activities that are supplementary, the view to enlarge the burden of the studio remains the primary choice in designing formal education in architecture.

In every architecture education, design studio courses always use more or less the same scheme. Each class begins with a project or problem case study, site and context, and a

\footnotetext{
${ }^{2}$ Cited from Kreiner (2010) in Kamstrup (2017)

${ }^{3}$ Cited from Gasset (1997) in Orhan (2017)
}

${ }^{4}$ Cited from Caglar (2009) in Orhan (2017)
${ }^{5}$ Cited from Yurekli \& Yurekli (2004) in Orhan (2017) 
questions focused on finding information related to students'

binding time limit. Then each student develops a design based on their research and study to generate a product that will be discussed or tested by the teacher. The atmosphere of the design competition and the effort to provide the best products is often seen in the architectural studio course. In general, the best work then receives various benefits that may differ from each school.

The above is not surprising because the competition is the origin and perhaps the only way of education in architecture that has remained in use since the founding of the first architectural school (Ecole des Beaux-Arts) in France [3]. The system applied in architecture lectures is a reflection of the design competition system. The only thing that distinguishes studios and competitions is the role of lecturers who act as mentors, as well as senior architects, clients, juries, and sponsors in architectural education.

However, architectural education through traditional studios alone is not sufficient to equip architecture understanding for students [5]. Students need to gain handson experience because according to Costa ${ }^{6}$, "architecture cannot be taught, and the best learning method is to do it." Therefore, architectural exercise outside of the formal educational system may still be the best way to equip students with design skills. One of the media to provide that experience is to join a real architectural competition.

Apart from these reasons, architectural competition can be a good supplement for formal education because it cannot be denied that architectural design studies carried out within the scope of the studio are always concerned with design approval by educators. Students only focus on how they can graduate from the studio classes that they followed. Architectural education that applies similar methods will harm students. Traditional architectural education methods that prioritize the principle of master-apprentice relations are often far from the purpose of study, which should prioritize student creativity. Lack of freedom and a lack of desire to transform resulted in a strict learning approach and inefficiency of internal management mechanisms [5].

An architectural competition is another method for practicing and learning how to become an architect, which also includes an opportunity greater than winning a prize. Even a loss in the competition can be an opportunity to test and develop specific aspects of the architect's work. The competition can be seen as the architect's only opportunity to be able to freely develop new skills, as well as knowledge and ideas to move forward. An architectural competition provides an opportunity to formulate an idea that might not be explored daily [3].

\section{METHODS}

This research is a reflective evaluation using a quantitative approach through a questionnaire distributed to active students or fresh graduates of the Department of Architecture in Universitas Islam Indonesia who have participated in an architecture competition either held both at home country and abroad. The study was conducted between March and August 2019 with purposive sampling.

Questions asked to include personal data and items that focus on participation in architectural competitions. Specific first time to take part in the competition, the development of the individual study when the research was carried out, and the motivation to participate. The questionnaire also asks the student on the scope of the competition that first followed, the number of participation, achievements, and benefits gained from the competition.

The questionnaire given also included questions that were subjective reflections addressed to respondents regarding the benefits derived from participating in the competitions. There is 10 statement about the benefits of participation in the competition that are measured using a Likert Scale ranged from 1 to express strong disagreement up to 4 to express strong agreement. These 10 points are based on the essential competencies that must be obtained by students in architectural education as stipulated in the UIA-UNESCO Architectural Education Charter, namely design, skill, knowledge.

The statement includes the respondent's approval of the competition benefits, which include (a). Significantly improve the ability to design; (b). Add new insights not given in lectures; (c). Increase the ability to socialize through teamwork; (d). Increase time management capabilities; (e). Increase skills in using architectural software and visualizations; (f). Add skills to deliver presentations orally (both in Bahasa Indonesia and foreign languages); (g). Add skills to convey ideas through writing; (h). Enhance the experience through field studies conducted; (i). Increase understanding of contextual matters that occur in society, and j). Provide financial benefits. The structure of all questions is deliberately made in a positive form so that the same results obtained.

\section{DISCUSSION}

\section{A. Profile of the Respondents}

Profile of respondents in this study included 24 students or alumni from the year of 2014 (16.7\%), 2015 (4.2\%), 2016 (25\%); 2017 (25\%); and 2018 (29.2\%). Most (87.5\%) of the respondents were active students, and the rest $(12.5 \%)$ were graduates who worked. All graduate respondents have worked in institutions engaged in architecture.

The first semester the respondents took part in the competition was quite varied. Students who first participate in the competition in their first semester a total of $29.2 \%$ and the second semester amounted to $33.3 \%$. Those to be the majority of the first entrance of student participation in the architectural competition. Furthermore, the third and fourth semesters, each amounted to $12.5 \%$, the fifth semester amounted to $8.3 \%$, and only $4.2 \%$ of students started participating in the competition above the seventh semester. The average semester of the respondent when they first attended the competition is 2.54 or approximately starting to join between the 2nd and 3rd semester of the lecture.

The scope of building design is the most competition theme followed by respondents when they first participated, covering $58.3 \%$. Design competition as a conceptual idea or work of art is the first competition theme by $25 \%$ of respondents. Only $4.2 \%$ of participants who took part in the first competition with the theme of interior design, and another

\footnotetext{
${ }^{6}$ Cited from Costa (2014) in Guilherme (2014)
} 
entry point that influences how quickly new students can receive information about the competition.

The development of technology and the ease of accessing information encourage students to be able to choose and develop the passion they want to pursue. The same thing also applies to the process of architectural education. The positive benefits of information technology in the architecture world should not only stop as a way to get references from cyberspace but also to develop soft and other hard skills that can be trained in the real world.

Eligibility and entry points in competition participation are not limited to final semester students. On many occasions, the competitions held were not only limited to professional competitions but were more inclusive and allowed students to participate. Therefore, the teacher's role is also vital in introducing architectural competitions to students as another method for developing themselves and practicing skills in designing outside of formal lectures.

Social circle support was seen in the high percentage of respondents who participated in the group in the first architectural competition. However, it can be assumed that the high number of respondents participating in the team is only a requirement for participation in the competition. The effectiveness in designing and the opportunity to enter the nomination, let alone win the competition, cannot necessarily be directly proportional to the number of registered members in the team. Especially in the case of participation in the first competition, it is uncommon that at the first opportunity to enter a competition where participants can directly enter the nomination or even advance as winners.

Through the questionnaire, the respondents' reflections on the study activities were also known when they first participated in the competition. $70.8 \%$ of respondents stated that participation in the competition did not interfere with their study, and only $29.2 \%$ stated that it had interfered with the study. Nonetheless, from the feedback received in the questionnaire, we could find concern about the conflict between the lecture deadline and the competition that was followed, as well as the limited time available for respondents outside the obligation to run their respective architectural studio projects.

Based on the questionnaire, it is known that the highest score given by respondents in the statement that the architectural competition can add new insights that are not given in lectures, with an average of 3.79. From this point, some interesting things can be identified related to the benefits of the architectural competition. The broad scope of study in the field of architecture allows several things not entirely conveyed to students. The architectural competition offers more opportunities for students outside of lectures to recognize the intricacies of the world of architecture that may not have been touched at formal study sessions. Not infrequently, the case given in the competition is a very new insight and experience, or even completely different compared to the material that usually found in lectures.

The above also includes insights in the form of opportunities to explore certain parts of an area as part of the observation process to formulate appropriate design concepts. Exploration and observation, in this case, are not limited to actual surveys, but also enrichment of students' understanding called architectural competition. In this case, the circle of friendship and the atmosphere of the early studio class is an 
and insight through mass media, social media, and the internet.

TABLE I. BENEFITS FROM THE ARCHITECTURAL COMPETITION

\begin{tabular}{|c|l|c|}
\hline Rank & \multicolumn{1}{|c|}{$\begin{array}{c}\text { Things gained from participating in an } \\
\text { architectural competition }\end{array}$} & $\begin{array}{c}\text { Average } \\
\text { score }\end{array}$ \\
\hline 1. & Can add new insights not given in lectures & 3,79 \\
\hline 2. & Can add time management capabilities & 3,75 \\
\hline 3. & $\begin{array}{l}\text { Can add skills using architectural software and } \\
\text { visualization }\end{array}$ & 3,75 \\
\hline 4. & Can increase in significant design capabilities & 3,67 \\
\hline 5. & Can add the ability to socialize through teamwork & 3,63 \\
\hline 6. & $\begin{array}{l}\text { Can improve understanding of contextual matters } \\
\text { that happen in society }\end{array}$ & 3,63 \\
\hline 7. & $\begin{array}{l}\text { Can add skills to deliver presentations oral (both } \\
\text { in Bahasa Indonesia and foreign languages) }\end{array}$ & 3,58 \\
\hline 8. & $\begin{array}{l}\text { Can enhance experiences through field studies } \\
\text { conducted }\end{array}$ & 3,54 \\
\hline 9. & Can add skills to convey ideas through writing & 3,46 \\
\hline 10. & Can provide financial benefits & 3,25 \\
\hline
\end{tabular}

The opportunity to visit other cities, or even the chance to travel abroad is an additional benefit that can broaden students' insights through competition participation. This is possible in multistage competitions, which usually require a design presentation to the jury after several nominees have been announced. Even at prestigious competitions, nominees are invited to the final event to present their work and receive awards held at a place. This, in essence, can be seen as allowing experiencing a new insight for students that are not obtained in lectures.

The high score in the form of benefits in the way of adding new insights can also be interpreted as an opportunity to make a leap of study for participants. As is well known in the respondent's profile, the average semester when the respondent participates in the first competition is between the 2nd and 3rd semester or about at the end of the first year and beginning of the second year of study. In this relatively short period, it can be assumed that the study material obtained was limited compared to the students in the later semester. Instead of gaining architectural insights through formal lecture levels, respondents had the opportunity to learn about material that had not been delivered through the competition. This method of learning is not only limited in the form of reading materials and creativity of design but also in the way of learning opportunities through discussions between seniors and juniors that enable the transfer of knowledge in a broader sense.

The next highest average score is on the statement that the competition can add time management capabilities, and it can add to the skill of using architecture and visualization software, namely with each average of 3.75 . It is generally understood that studies in architecture are closely related to personal time management and the ability to present ideas through drawings. By participating in the competition, respondents felt they benefited in the form of both skills that could be used in the future.

The ability to manage time is one of the soft skills that need to be developed and inherent problems that are often encountered by architecture students. Amid the high demands of studio deadlines, students who succeed in taking the time to be able to develop themselves, either through competitions or extra-curricular activities, are suspected of having a higher ability to adjust than other students who do not move outside the classroom. Besides, students can also learn to adapt their schedule to other teammates and learn to understand their responsibilities in terms of work time.

Today, presentation skills with rendering images are closely related to the ability to master architectural software and 3-dimensional visualization. The opportunity to explore design with the help of computers is another benefit gained from participating in the competition. In the early semester of lectures at the Department of Architecture UII, students are required to design manually, and some restrictions are strict enough not to design with computers before the 2nd year. Participation in the competition often considered an opportunity to learn computer modeling skills that have not given through lectures. In the case of a team consisting of different year students, the senior role as a mentor in the development of design and visualization by computer means is enormous. Such learning systems are suspected to be more effective when compared to formal lecture sessions.

The point that competition is useful to improve the ability to design significantly gets an average score of 3.67. The rating given for this point is ranked the third, which is lower than adding insight, time management capabilities, and software usage skills. This can be interpreted that increasing the ability to design is not the main thing that is sought from participation in the competition. Some respondents thought that participation in the competition could be considered as a supplement to studio lectures that were useful for improving their design. Whereas some respondents felt that the opportunity to enhance their design in the competition continued to occur, but the respondents assumed the increase that occurred was not too significant.

Respondents think that their ability to design has improved because design development through competitions is freer and is not limited by teachers. On the other hand, the inherent demands in the competition to showcase the best work and in a short time, become pressures that encourage students to be able to think critically. Respondents also benefit in the form of opportunities to conduct benchmarking studies with previous works and make comparisons with products from abroad to improve their design capabilities. By participating in the competition, students are also encouraged to be able to follow the design and presentation standards at a higher level.

The next average ranking score is for the point of statement that architectural competitions can increase the ability to socialize through teamwork and can increase understanding of contextual matters that occur in the community. The two things each get an average of 3.63. The high number of participation in team competitions requires respondents to be able to socialize and cooperate in teams. Respondents think that by participating in the competition, the opportunity to socialize and increase network becomes greater. Besides, the indirect benefits of socializing delivered by respondents included more profound opportunities to discuss, exchange ideas, recognize different perspectives, take lessons from senior experience, become more free to think and accept opinions. 
Often, amid tight deadline schedules, architecture students become less sensitive to the actual and current issues that occur in society. Respondents saw an opportunity to gain firsthand experience found in the community by participating in the competition. Problems raised in the competition are often rare - or never - encountered by students or raised in the studio process. This is what drives students to be more able to go down to the community, try to understand contextual issues that occur, and formulate appropriate design concepts to answer them.

In the next rank, respondents thought that the architectural competition was useful to be able to increase their skills in delivering oral presentations, both in Indonesian and foreign languages, with an average of 3.58. The average is somewhat higher compared to the value given for the benefits gained in the form of presentation skills through writing. The response obtained is suspected of having something to do with the fact that oral media is still the most effective method of conveying ideas at the conception stage of ideas. Although today the role of communication through digital media and using text is quite developed, to express ideas through direct means and use speech are considered more comfortable to use.

This thing can also be considered as a form of expression of respondents who are not too concerned about the aspect of presentation written on posters or other products collected because one particular team member will only do this section. On the other hand, a multistage type competition requires an oral presentation before a jury. This is what makes students seem to prioritize the importance of oral presentations compared to writing.

With an average of 3.54 , respondents agreed that architectural competitions could enhance the experience through field studies. Many competitions take up the theme of common conditions in society, and only a few competitions have a conceptual, fantasy, and ideal situation as themes. By participating in the competition, respondents considered that the opportunity to improve their experience in the field was greater. This is suspected to be in line with the value given for the benefit of increasing understanding of conceptual matters that occur in society. However, because not all competitions require to conduct surveys and field studies, respondents consider the benefits gained through this point not to be as large as the benefits in the conceptual terms explained in the previous section.

Points to the benefits that architectural competitions can add to the skill of conveying ideas through writing are ranked low. The average value given by respondents was only 3.46. This does not mean that writing skills are not needed at all in architecture. However, it is suspected that students thought that writing presentations might less important in submitted products compared to visual presentations and oral presentations. Therefore, the existence of written presentation skills is mostly ignored.

At the lowest rank, namely, with an average score of 3.25 is for the value given by respondents at the point of the architectural competition can provide financial benefits. This is thought to represent the motivational representation of the majority of respondents who consider the competition to be only a place to hone their abilities, seek experience, and add to their portfolio. Although the prizes offered are sometimes necessary gimmicks in attracting participation in a competition, some respondents do not consider financial gain as the primary motivation.

Although some respondents were participants who had won several competitions, financial benefits were not overly displayed and overshadowed with gains in other forms, such as experience and particular skills. For respondents who have won a competition, the prize obtained means as a motivating booster and a lure for them to participate in other competitions in the future. It serves as well as the opportunity to show achievement with a more prestigious portfolio.

With the above results, it can be understood the important role of architectural competitions as a supplement in architecture education, primarily through student perspectives. The architecture competition is encouraging students to get out of their comfort zone and learn to produce the best design in a short time, as Guilherme [3] mentions. Freedom in designing beyond the framework of studios and lectures can be seen as an excellent opportunity to hone the architectural skills for students.

As mentioned in the beginning, the paradigm change in architecture education needs to be able to accommodate and be flexible to change. Inclusion architecture competition to the education curriculum does not necessarily guarantee students will be able to design very well. However, giving more appreciation to the students who participated in the competition can be a good starting step in fostering an architectural passion. Perhaps the process of growing much more valuable in education than a way that seemed more integrative.

\section{CONCLUSION}

Based on the above explanation, it can be concluded several essential points. First, the most important benefit of participating in architectural competitions felt by students is that they can add new insights that are not obtained through lectures. This point is in the first rank to surpass the other benefits pointed out in questionnaires, such as improving the ability to design, the ability to socialize through teamwork, and the ability to manage time. It also has a higher score than the skills to use architectural software and visualization, the skills to deliver oral and written presentations, additional experiences through field studies, understanding of contextual matters that are happening, and financial gain.

For architecture students, the opportunity to gain new experiences is essential to get as early as possible. By participating in architectural competitions, students can face challenges and have the chance to develop themselves through informal activities outside of lectures. This, in turn, will help students develop their passion in architecture, while at the same time forming pride, mentality, skills, knowledge, and design skills that are superior to their peers who do not participate.

Conversely, the benefits of architectural competitions in the form of financial gains are the lowest points. Financial rewards offered in competitions are not always the final destination. Although up to a certain level, it is undeniable that the opportunity for students to win a competition will get something valuable and prestigious. Victory or defeat does not seem to be a point that always comes first. It can be assumed that from the perspective of students, getting new skills and 
additional portfolios has more valuable value than mere financial benefits.

Second, the thing that motivates students to participate in the competition is to try on their initiative, while the most significant source of information about the competition comes from social media. Developing information technology also increases students' exposure to awareness of informal learning means in the competition. The friendship closest circle and the learning atmosphere in their early semester also influenced their desire to participate in the competition. This needs to be seen as an opportunity to increase students' study potential and equip students with valuable experience.

There are some limitations in this study, as the number of respondents participating in the survey was still small. Also, it is not yet known the impact of competition for students regarding learning outcomes and the quality of designing skills after participation. Further research can expand the scope of respondents with broader coverage and more extended time. This is to be able to see discourse related to architecture competition with various consequences on students.

While there seems to be an implied connection between participation in the competition and the general improvement of the student's ability, the apparent relationship between the two is uncertain in this study. This is due to the lack of data that can be used to find the relationship between the two. Subsequent research can address this and make it a focus of research.

Another thing that may be discussed in advanced research is to see changes in students' motivation when participating in competitions after winning an event. It is necessary to consider the impact of the earned reward can change the student's perception to follow another competition. It would be exciting to know how the decision-making process takes place on the students who have won the competition in the face of bids following later events.

Finally, participation in the competition brings many positive impacts on students. Teachers and educational institutions should be able to open as many opportunities as possible for students to participate in architectural competitions. Flexibility in designing studio lectures that allow students to take part in the competitions is also needed. If directed properly, the combination of formal and informal education can open more opportunities for students to be more creative and hone their skills.

Encouragement from teachers to students is also needed so that students can achieve a better achievement in the future. In essence, by participating in the competition, both institutions and students alike will benefit. Institutions also get recognition from various stakeholders, especially if students win the competition that is followed. This kind of mutual relationship, in the long run, will create a more sustainable architecture education system.

\section{ACKNOWLEDGMENT}

We would like to thank Allah for all of the blessings to us. Also, to our family, friends, students, and colleagues in the Department of Architecture Universitas Islam Indonesia for the support, insights, and suggestion during the course of this research.

\section{REFERENCES}

[1] J. E. Andersson, G. B. Zettersten and M. Rönn, "Introduction," in Architectural Competitions as Institution and Process, The Royal Institute of Technology and Kulturlandskapet, 2016.

[2] International Union of Architects, UIA COMPETITION GUIDE FOR DESIGN COMPETITIONS IN ARCHITECTURE AND RELATED FIELDS, Seoul, 2017.

[3] P. M. H. S. Guilherme, "Competitions serve a larger purpose in architectural knowledge," in Fourth International Conference on Architectural Research by Design (ARbD'14), 2014.

[4] A. Kamstrup, Crowdsourcing and the architectural competition as organisational technologies, Copenhagen: Copenhagen Business School., 2017.

[5] M. Orhan, "The Role and Importance of Workshops in the Architectural Design Education; Case of "Self Made Architecture I-II"," New Trends and Issues Proceedings on Humanities and Social Sciences., no. 03, pp. 131-136, 2017.

[6] UNESCO-UIA, UNESCO-UIA CHARTER FOR ARCHITECTURAL EDUCATION, Paris: International Union of Architects, 2017. 